\title{
Suppressing Effect of Lithium Dendritic Growth by Addition of Magnesium Bis(trifluoromethanesulfonyl)Amide
}

\author{
Masahiro Shimizu, ${ }^{* a b}$ Makoto Umeki, ${ }^{\mathrm{a}}$ and Susumu Arai ${ }^{* a b}$ \\ ${ }^{a}$ Department of Materials Chemistry, Faculty of Engineering, \\ Shinshu University, 4-17-1 Wakasato, Nagano, 380-8553, Japan \\ ${ }^{\mathrm{b}}$ Institute of Carbon Science and Technology, Faculty of Engineering, \\ Shinshu University, 4-17-1 Wakasato, Nagano, 380-8553, Japan
}

*Corresponding author

Assistant Prof. Masahiro Shimizu

E-mail: shimizu@shinshu-u.ac.jp

Tel.: +81-26-269-5627; Fax: +81-26-269-5627

Prof. Susumu Arai

E-mail: araisun@shinshu-u.ac.jp

Tel.: +81-26-269-5413; Fax: +81-26-269-5432

Electronic Supplementary Information (ESI) available: Cyclic voltammogram of Li deposition/dissolution in a conventional electrolyte, enlarged views of FE-SEM images and XRD patterns of various deposits obtained from $x \mathrm{M} \mathrm{Mg(TFSA})_{2}+(1-x) \mathrm{M} \mathrm{LiTFSA} / \mathrm{G} 3(x=0,0.1$, 0.5). See DOI: 10.1039/x0xx00000x. 


\begin{abstract}
Practical applications of Li-S and Li-air batteries require the morphology of the Li metal negative electrode during charge/discharge (i.e., Li-deposition/dissolution) cycling to be precisely controlled. Herein, we used magnesium bis(trifluoromethanesulfonyl)amide $\left[\mathrm{Mg}(\mathrm{TFSA})_{2}\right]$ as an electrolyte additive to suppress the growth of Li dendrites, utilizing the occurrence of an alloying reaction between the initially substrate-deposited $\mathrm{Mg}$ and the subsequently deposited Li. Notably, no metallic $\mathrm{Mg}$ formation and no change in Li deposition morphology were observed at an electrolyte composition of $0.1 \mathrm{M} \mathrm{Mg(TFSA})_{2}+0.9 \mathrm{M} \mathrm{LiTFSA/triglyme,} \mathrm{irrespective} \mathrm{of} \mathrm{the}$ applied potential. In contrast, increasing the $\mathrm{Mg}$ salt concentration to $0.5 \mathrm{M}$ resulted in the deposition of interconnected granules, reflecting a dramatic morphology improvement. X-ray diffraction analysis revealed the occurrence of the abovementioned alloying, which finally afforded a deposit composition of $\mathrm{Li}_{0.9} \mathrm{Mg}_{0.1}$ via the formation of an intermediate $\mathrm{Li}_{0.14} \mathrm{Mg}_{0.86}$ phase. Importantly, the deposits obtained under various applied potentials were relatively smooth, with no needle-like morphology observed.
\end{abstract}

Keywords: Li battery; Li metal; Polyvalent metal ion; Negative electrode; Dendrite 


\section{INTRODUCTION}

The rapidly progressing applications of Li-ion batteries (LIBs) as large-scale power sources in electric vehicles and smart grids aid the realization of a low-carbon society, making Li metal a very promising negative electrode material in view of its high theoretical capacity of $3860 \mathrm{mAh}$ $\mathrm{g}^{-1}$ compared to that of the conventionally used graphite ( $\left.\mathrm{LiC}_{6}: 372 \mathrm{mAh} \mathrm{g}^{-1}\right){ }^{1-4}$ However, $\mathrm{Li}$ metal is inherently unsuitable for use in rechargeable batteries due to posing certain safety risks. For instance, repeated Li deposition/dissolution during charge/discharge can result in a thermal runway and cause serious accidents due to the deposition of $\mathrm{Li}$ dendrites that penetrate the separator and thus induce internal short-circuiting. ${ }^{5}$ Hence, a number of approaches have been developed to prevent the growth of Li dendrites, e.g., the use of three-dimensional matrix substrates, ${ }^{6-8}$ electrolyte additives, ${ }^{9-12}$ and the introduction of a solid electrolyte between the Li electrode and the electrolyte solution. ${ }^{13,14}$ Thus, Kim et al. introduced a fibrous metal felt (FMF) as a three-dimensional conductive interlayer at the interface between the separator and the Li metal electrode, improving the cycling performance of $\mathrm{Li} / \mathrm{LiFePO}_{4}$ cells. ${ }^{7}$ Therein, the FMF acted both as an electrically conductive pathway for enhanced charge transfer in the porous layer and as a robust scaffold compactly accommodating Li deposits in its internal sites. Zhang et al. succeeded in controlling Li deposit morphology with high coulombic efficiency by using a superconcentrated electrolyte, namely $4 \mathrm{M}$ lithium bis(fluorosulfonyl)amide (LiFSA) dissolved in 1,2dimethoxyethane. ${ }^{15}$ The use of electrolyte additive such as vinylene carbonate (VC) ${ }^{16}$ and fluoroethylene carbonate (FEC) ${ }^{17}$ enable high reversibility of Li-deposition/dissolution by the passivation originated from the formation of uniform solid electrolyte interphase (SEI). However, the SEI-forming additives are gradually expendable as charge/discharge cycle progresses. In order to construct SEI film with high durability in long-term cycling, a greater quantity of SEI must be 
formed, in which case it induces a large overvoltage. In another study, Zhang et al. modified an electrolyte by addition of $\mathrm{Cs}$ and $\mathrm{Rb}$ ions to form a positively charged electrostatic shield around the initial protuberance growth tip to achieve Li deposit leveling. ${ }^{12}$ Thus, the suppression of Li dendrite growth by electrostatic control based on the standard electrode potential difference was demonstrated to be an extremely simple and effective method. In contrast, our strategy relied on using an electrolyte containing a salt of a metal (e.g., $\mathrm{Mg}$ or $\mathrm{Al}$ ) capable of electrochemical alloying with $\mathrm{Li}^{18-20}$ In an electrolyte comprising both $\mathrm{Li}$ and $\mathrm{Mg}$ salts, Mg ions should be reduced in preference to $\mathrm{Li}$ ions and form a deposit of metallic Mg due to the higher electrode potential of $\mathrm{Mg}$ compared to that of $\mathrm{Li}\left(-2.36\right.$ vs. $-3.04 \mathrm{~V}^{20}$ relative to the standard hydrogen electrode, respectively). Subsequently, $\mathrm{Li}$ deposition is expected to proceed on the previously deposited $\mathrm{Mg}$ to generate $\mathrm{Li}-\mathrm{Mg}$ alloys. Even in the case of initial excessive Li dendrite formation, the reduction of Mg ions estimated to occur in the region of high applied electric field should result in the formation of a $\mathrm{Li}-\mathrm{Mg}$ alloy and thereby suppress further morphological changes. If the reaction occurs reversibly, $\mathrm{Mg}$ only dissolved and deposits between the electrolyte and the substrate, and Mg source should be not consumed even in long-term cycles, unlike SEI-forming electrolyte additives. The addition effect of alkaline-earth metal ion $\left(\mathrm{Mg}^{2+}, \mathrm{Ca}^{2+}, \mathrm{Sr}^{2+}, \mathrm{Ba}^{2+}\right)$ to quaternary ammonium-based ionic liquid electrolytes on Li deposition morphology has already reported by other researchers ${ }^{21}$, whereas we focused on addition into glyme-based organic electrolytes in the present study. Herein, we mainly examined the deposition and alloying behavior of $\mathrm{Li}$ in the presence of different concentrations of $\mathrm{Mg}(\mathrm{TFSA})_{2}$ under constant potential conditions. 


\section{EXPERIMENTAL SECTION}

$\mathrm{LiPF}_{6}, \mathrm{LiTFSA}, \mathrm{Mg}(\mathrm{TFSA})_{2}$, ethylene carbonate (EC), diethyl carbonate (DEC), and triethylene glycol dimethyl ether (triglyme, G3) were purchased from KISHIDA Chemical Co., Ltd. and used without further purification, and 1.0 M LiPF $/$ EC:DEC (50:50 v/v) was employed as a commercially available electrolyte. To suppress the growth of Li dendrites, electrolytes with compositions of $x$ M Mg(TFSA $)_{2}+(1-x)$ M LiTFSA/G3 $(x=0.1,0.5,1.0)$ were prepared. Interactions between Li/Mg ions and G3 were investigated by Raman spectroscopy (T64000 Advanced Research Raman System, HORIBA Ltd.) using the $532 \mathrm{~nm}$ line of a Nd:YAG laser at room-temperature. To eliminate the influence of atmospheric moisture, samples were placed into a quartz cell that was tightly sealed in an Ar atmosphere. Electrochemical tests were performed utilizing three-electrode cells comprising a $\mathrm{Cu}$ (diameter: $10.8 \mathrm{~mm}$, thickness: $18 \mu \mathrm{m}$; Nilaco Co., Ltd.) working electrode, Li foil (99.90\%; Rare Metallic) counter and reference electrodes, and the abovementioned electrolytes. Prior to cell fabrication, the $\mathrm{Cu}$ substrate was degreased by sequential immersion into an alkaline detergent (C-4000; C. Uyemura \& Co., Ltd.) solution and dilute sulfuric acid at $60{ }^{\circ} \mathrm{C}$. Electrolyte preparation and cell assembly were performed in an Arfilled glove box with a dew point below $-80{ }^{\circ} \mathrm{C}$. Li deposition and dissolution in various electrolytes were studied by cyclic voltammetry (CV), with the corresponding data recorded at a sweep rate of $0.1 \mathrm{mV} \mathrm{s}^{-1}$ using an electrochemical analyzer (SP-200; Bio-Logic Science Instruments). Li deposit morphology was characterized by field-emission scanning electron microscopy (FE-SEM; JSM-7000F; JEOL Co., Ltd.), and the corresponding crystal structures were determined by X-ray diffraction (XRD, SmartLab; Rigaku) using $\mathrm{Cu}$ Ka radiation. 


\section{RESULTS AND DISCUSSION}

The developed strategy relied on the formation of $\mathrm{Mg}$ deposits and subsequent $\mathrm{Li}-\mathrm{Mg}$ alloying for smooth Li deposition. However, the addition of Mg salts to a conventional organic electrolyte used in LIBs (1 $\left.\mathrm{M} \mathrm{LiPF}_{6} / \mathrm{EC}: \mathrm{DEC}\right)$ did not result in Mg deposition (data not shown). Herein, we chose the combination of $\operatorname{Mg}(\mathrm{TFSA})_{2}$ as a magnesium salt and G3 as an electrolyte solvent, which was reported to facilitate reversible Mg deposition/dissolution. ${ }^{22-25 .}$ Figure 1 shows the Raman spectra of electrolyte solutions comprising $x$ M Mg(TFSA) $)_{2}+(1-x)$ M LiTFSA/G3 ( $x$ $=0,0.1,0.5$ ) recorded in the range of $780-900 \mathrm{~cm}^{-1}$. The Raman spectrum of pure G3 shows bands assigned to $\mathrm{CH}_{2}$ rocking and $\mathrm{C}-\mathrm{O}-\mathrm{C}$ symmetric stretching vibrations. ${ }^{22,26}$ Upon the addition of LiTFSA to G3, a new band appeared at $864 \mathrm{~cm}^{-1}$, reflecting the interaction of G3 with $\mathrm{Li}$ ions to form $\left[\mathrm{Li}(\mathrm{G} 3)_{n}\right]^{+}$complexes. ${ }^{27,28}$ On the other hand, a shoulder peak ascribed to $\left[\mathrm{Mg}(\mathrm{G} 3)_{n}\right]^{2+}$ was also observed in the $0.1 \mathrm{M} \mathrm{Mg(TFSA)} / 2 / 0.9 \mathrm{M} \mathrm{LiTFSA} / \mathrm{G} 3$ system, indicating the co-existence of two complexes in the above electrolyte. The signal intensity of $\left[\mathrm{Mg}(\mathrm{G} 3)_{n}\right]^{2+}$ increased with increasing $\mathrm{Mg}$ concentration $(x=0.5)$. In the case of pure $\mathrm{Mg}(\mathrm{TFSA})_{2}$ dissolved in G3 (i.e., in the absence of LiTFSA), the Mg ion was reported to be solvated either by two tridentate G3 molecules or by one tetradentate and one bidentate G3 molecules. Based on the density functional theory calculations of Fuji et al., the above species exhibit Raman bands at 889.4 and $877.4 \mathrm{~cm}^{-1}$, respectively. ${ }^{26}$ Since we observed both of these signals, $\mathrm{Mg}$ ions were probably coordinated by two G3 molecules to form a $\left[\mathrm{Mg}(\mathrm{G} 3)_{2}\right]^{2+}$ complex even in the presence of Li ions, although the exact solvation state was not identified.

The deposition of $\mathrm{Li}$ in the presence of Mg ions was examined by CV (Figure 2). As a result, 1 M LiTFSA/G3 showed paired cathodic (Li deposition) and anodic (Li dissolution) peaks at -0.5 and $0.24 \mathrm{~V}$ vs. $\mathrm{Li}^{\prime} / \mathrm{Li}^{+}$, respectively, with the introduction of $0.1 \mathrm{M} \mathrm{Mg}(\mathrm{TFSA})_{2}$ resulting in 
no remarkable changes. However, a broad cathodic peak between 0.6 and $-0.05 \mathrm{~V} v \mathrm{vs}$. $\mathrm{Li}^{2} / \mathrm{Li}^{+}$was observed for $0.5 \mathrm{M} \mathrm{Mg}(\mathrm{TFSA})_{2}$, with the fact that the standard electrode potential of $\mathrm{Mg}$ is higher than that of Li by $0.68 \mathrm{~V}$ implying that this peak was due to Mg deposition. Thus, Mg deposition did not proceed in $0.1 \mathrm{M} \mathrm{Mg(TFSA})_{2}+0.9 \mathrm{M}$ LiTFSA/G3. The cathodic response of the above system below $0 \mathrm{~V}$ was ascribed to $\mathrm{Li}$ deposition or $\mathrm{Li}-\mathrm{Mg}$ alloying reactions. Interestingly, only one anodic (dissolution) peak was observed, with its potential being lower than that of other electrolytes, whereas the introduction of $0.1 \mathrm{M} \mathrm{Mg(TFSA})_{2}$ resulted in the appearance of two separate peaks. However, since the effect of Mg salt addition on Li deposition was difficult to determine, we investigated the morphology of $\mathrm{Li}$ deposits formed during constant-potential electrolysis at $-0.2,-0.4$, and $-0.8 \mathrm{~V}$ vs. $\mathrm{Li} / \mathrm{Li}^{+}$.

Figure 3 shows FE-SEM images of deposits obtained at certain applied potentials and times in electrolytes containing $\mathrm{Li}$ and $\mathrm{Mg}$ salts. The use of a Mg-free electrolyte (i.e., $1 \mathrm{M}$ LiTFSA/G3) inevitably resulted in dendrite formation, regardless of applied potentials and times, with the deposit morphology being not different from that observed for a conventional electrolyte (1 M $\mathrm{LiPF}_{6} / \mathrm{EC}: \mathrm{DEC}$; Figure S1). In particular, the produced acicular Li deposits resulted in short circuit formation, thus causing battery thermal runaway (Figure S2). However, dendrite growth was slightly suppressed in the case of $0.1 \mathrm{M} \mathrm{Mg(TFSA})_{2}$. In this case, the Li deposit comprised a certain amount of fine needles, and Li gradually grew in the vertical direction with time upon the application of a constant potential of $-0.2 \mathrm{~V}$ vs. $\mathrm{Li} / \mathrm{Li}^{+}$(Figure S3). Li existed as particles and acicular shape below $-0.4 \mathrm{~V}$ vs. $\mathrm{Li} / \mathrm{Li}^{+}$, and metallic Mg was not detected from XRD patterns of the deposits in any case (Figure S4). In contrast, in the case of $0.5 \mathrm{M} \mathrm{Mg(TFSA)2,} \mathrm{spherical}$ deposits attributed to metallic Mg were observed after 3 min when a potential of $-0.2 \mathrm{~V} \mathrm{vs}$. $\mathrm{Li} / \mathrm{Li}^{+}$ was applied, with the above deposits growing and retaining their morphology up to a time of 30 
min. After 30 min, high-resolution imaging revealed the formation of needle-like Li deposits, which, however, could not be detected by XRD. Li can react with Mg to form solid solutions of broad composition, and the single BCC phase solid solution alloys exists over 11.5-100 wt.\% Li in $\mathrm{Li}-\mathrm{Mg} .{ }^{17}$, presumably explaining why Li was not detected by the above XRD experiments. A comparatively smooth deposit was obtained after $10 \mathrm{~h}$, comprising $\mathrm{Mg}$ and $\mathrm{Li}_{0.9} \mathrm{Mg}_{0.1}$. Although the above deposit corresponded to a Li-rich phase, no dendritic morphology was observed, implying that the electrochemical formation of $\mathrm{Li}-\mathrm{Mg}$ alloys played a key role in suppressing surface morphology change. Notably, deposits comprising interconnected grains were observed at all times at an applied potential of $-0.4 \mathrm{~V}$ vs. $\mathrm{Li} / \mathrm{Li}^{+}$. XRD analysis (Figure 4) revealed that the previously formed $\mathrm{Mg}$ deposit underwent lithiation to form $\mathrm{Li}_{0.14} \mathrm{Mg}_{0.86}$ after 30 min and $\mathrm{Li}_{0.9} \mathrm{Mg}_{0.1}$ after $10 \mathrm{~h}$. Since the counter electrode comprising Li metal acted as a source of charge carrier ions in the electrochemical cell, the formation of $\mathrm{Li}$ deposits on the substrate with time is natural. Nevertheless, the suppression of dendritic growth of $\mathrm{Li}$ is very interesting. Furthermore, the effect of $\mathrm{Mg}$ salt addition became more pronounced at a potential of $-0.8 \mathrm{Vvs}$. $\mathrm{Li} / \mathrm{Li}^{+}$, when a dense $\mathrm{Mg}$ deposit was formed after $3 \mathrm{~min}$, with the reduction of $\mathrm{Li}$ ions after 10 min resulting in the deposition of Li metal on $\mathrm{Mg}$, with no $\mathrm{Li}-\mathrm{Mg}$ alloying yet occurring. Finally, the above alloying led to the formation of a smooth deposit $\left(\mathrm{Li}_{0.14} \mathrm{Mg}_{0.86}\right)$, with progressing lithiation affording $\mathrm{Li}_{0.9} \mathrm{Mg}_{0.1}$ while retaining smooth morphology (Figures S5 and S6). EDS mapping images (Mg$\mathrm{K} \alpha$ ) of the deposits also indicated the formation of $\mathrm{Li}-\mathrm{Mg}$ alloy (Figure S7). These changes in $\mathrm{Li}$ deposit morphology were also reflected in the time dependence of electrodeposition current density observed for various electrolytes.

Figure 5 displays chronoamperograms recorded at an applied potential of $-0.8 \mathrm{~V} \mathrm{vs.} \mathrm{Li} / \mathrm{Li}^{+}$, revealing that for $\mathrm{Mg}$ salt-free and $0.1 \mathrm{M} \mathrm{Mg(TFSA})_{2}$-containing electrolytes, the cathodic current 
densities rapidly increased from approximately -10 to $-20 \mathrm{~mA} \mathrm{~cm}^{-2}$, almost reaching a steady state after $1 \mathrm{~h}$. This sudden response was ascribed to the significant increase in the specific surface area of the formed deposit, i.e., Li dendrites. On the other hand, no such response was observed in the case of $0.5 \mathrm{M} \mathrm{Mg}(\mathrm{TFSA})_{2}$, which suggests the suppression of morphological changes. Indeed, the above cathodic behaviors were in good agreement with the results of FE-SEM imaging.

Based on the above, we concluded that the suppression of Li dendrite growth was induced by the electrochemical formation of a Li-Mg binary alloy (Figure 6). In electrolytes containing both $\mathrm{Li}$ and $\mathrm{Mg}$ salts, Mg ions, exhibiting a higher standard electrode potential than Li ions, are preferentially reduced to metallic $\mathrm{Mg}$ that is deposited on the substrate. Subsequent $\mathrm{Li}$ storage is enabled by the formation of $\mathrm{Li}-\mathrm{Mg}$ alloys (solid solutions) such as $\mathrm{Li} \mathrm{i}_{0.14} \mathrm{Mg}_{0.86}$ and $\mathrm{Li}_{0.9} \mathrm{Mg}_{0.1}$, which avoids dendrite formation. Even when Li dendrites are produced, the reduction of Mg ions in regions with a high applied electric field is thought to form the above alloys and thus suppress further morphological changes.

Finally, we investigated Li deposition morphology in different electrolytes under constant current condition and evaluated their Coulombic efficiency. Figure 7 shows charge-discharge curves at the first cycle and the 20th cycle under the constant current density of $0.1 \mathrm{~mA} \mathrm{~cm}{ }^{-2}$. FESEM images of deposits at the initial charge state $\left(1 \mathrm{~mA} \mathrm{~h} \mathrm{~cm}^{-2}\right)$ are also depicted. As with the results of constant potential electrolysis, Li dendritic growth was suppressed and the deposits became smooth with increasing $\mathrm{Mg}$ salt concentration in the electrolyte: the addition of $0.1 \mathrm{M}$ $\operatorname{Mg}(\mathrm{TFSA})_{2}$ made the diameter of needle-like deposit decrease, and deposit obtained from the addition of $0.5 \mathrm{M} \mathrm{Mg}(\mathrm{TFSA})_{2}$ resulted in mixed morphology consisted of spherical Mg metal and liner $\mathrm{Li}$ metal. Based on the results, a plateau observed at the potential of $0.1 \mathrm{~V} \mathrm{vs.} \mathrm{Li}^{\prime} / \mathrm{Li}^{+}$in 0.5 $\mathrm{M} \mathrm{Mg}(\mathrm{TFSA})_{2}+0.5 \mathrm{M} \mathrm{LiTFSA} / \mathrm{G} 3$ at the first cycle is originated from the Mg deposition and it 
is considered that $\mathrm{Li}$ deposition or $\mathrm{Li}-\mathrm{Mg}$ alloying reactions proceeded at subsequent region. However, although the cycling performance obtained from the electrolyte of $0.5 \mathrm{M} \mathrm{Mg}(\mathrm{TFSA})_{2}+$ 0.5 M LiTFSA/G3 was best among glyme-based electrolytes, their performances were by no means satisfactory. The main reason for the low Coulombic efficiency in Mg-free and $0.1 \mathrm{M}$ $\operatorname{Mg}(\mathrm{TFSA})_{2}$-added electrolytes is probably due to the decomposition of G3 solvent which is not involved in solvation. ${ }^{29,30} \mathrm{G} 3$ molecule has less electrochemical stability and surface layers induced by the electrolyte decomposition inhibits ion conduction. On the other hand, in $0.5 \mathrm{M}$ Mg(TFSA)2-added electrolyte, it is thought that the passivation of deposited Mg metal is responsible for the low efficiency: Mg metal could not dissolute as $\mathrm{Mg}$ ion to the electrolyte. In fact, XRD patterns measured at discharge state of $1.5 \mathrm{~V}$ in the first and the 10th cycle indicated that Mg metal remained on substrate as it was without dissolution (Figure S8). To enhance the Coulombic efficiency, that is, to achieve the reversible Mg-deposition/dissolution, we are now attempting to address the improvement of electrochemical stability and the optimization by the use of concentrated electrolyte and the addition of chloride.

Nevertheless, the obtained data raises some questions, i.e., whether the same behavior is observed if metallic Mg is used as a negative electrode from the beginning? Since the reactivity of alkaline earth metals toward air hinders their use as active electrode materials, the utilization of Mg ions in the electrolyte is preferred to the handling of metallic Mg as the negative electrode.

\section{Conclusions}

Herein, we examined Li deposition in Mg(TFSA)2-containing electrolytes using CV and constant-potential electrodeposition at various $\mathrm{Mg}$ salt concentrations and applied potentials. The 
use of a Mg salt-free electrolyte (1 M LiTFSA/G3) inevitably resulted in the growth of Li dendrites irrespective of the applied potential, with no improvements observed at a Mg(TFSA)2:LiTFSA molar ratio of 1:9. In contrast, $\mathrm{Mg}$ was deposited prior to $\mathrm{Li}$ in $0.5 \mathrm{M} \mathrm{Mg(TFSA})_{2}+0.5 \mathrm{M}$ LiTFSA/G3, which resulted in electrochemical Li-Mg alloying. In the above system, the products formed at various applied potentials after $10 \mathrm{~h}$ corresponded to $\mathrm{Li}_{0.9} \mathrm{Mg}_{0.1}$ and exhibited a relatively smooth morphology. However, under constant current condition, although Li dendrite morphology was suppressed with increasing Mg-salt concentration in the electrolytes, their Coulombic efficiencies were not high. This is probably because the ion conduction was inhibited by the surface layer induced by the electrolyte decomposition and the passivation of Mg metal suppressed the dissolution. To enhance Coulombic efficiency, we are attempting to address the improvement of electrochemical stability and the optimization of electrolyte composition.

\section{Conflicts of interest}

There are no conflicts to declare.

\section{Acknowledgments}

This work was supported by a Grant-in-Aid for Research Activity Start-up (No. 16H06838) from the Japan Society for the Promotion of Science (JSPS). The authors thank C.-S. Kang for his kind assistance during Raman measurements.

\section{Notes and references}

1. M.N. Obrovac, V.L. Chevrier, Chem. Rev., 2014, 114, 11444-11502.

2. Y. Sun, N. Liu, Y. Cui, Nat. Energy, 2016, 1, 16071.

3. D. Lin, Y. Liu, Y. Cui, Nat Nanotechnol., 2017, 12, 194-206. 
4. H. Wang, M. Matsui, H. Kuwata, H. Sonoki, Y. Matsuda, X. Shang, Y. Takeda, O. Yamamoto, N. Imanishi, Nat. Commun.. 2017, 8, 15106

5. F. Sun, R. Moroni, K. Dong, H. Markötter, D. Zhou, A. Hilger, L. Zielke, R. Zengerle, S. Thiele, J. Banhart, I. Manke, ACS Energy Lett., 2017, 2, 94-104.

6. D. Lin, J. Zhao, J. Sun, H. Yao, Y. Liu, K. Yan, Y. Cui, PNAS, 2017, 114, 4613-4618.

7. H. Lee, J. Song, Y.J. Kim, J.K. Park, H.T. Kim, Sci. Rep., 2016, 6, 30830.

8. S. Matsuda, Y. Kubo, K. Uosaki, S. Nakanishi, ACS Energy Lett., 2017, 2, 924-929.

9. X.B. Cheng, M.Q. Zhao, C. Chen, A. Pentecost, K. Maleski, T. Mathis, X.Q. Zhang, Q. Zhang, J. Jiang, Y. Gogotsi, Nat. Commun., 2017, 8, 336.

10. F. Ding, W. Xu, X. Chen, J. Zhang, Y. Shao, M.H. Engelhard, Y. Zhang, T.A. Blake, G.L. Graff, X. Liu, J.-G. Zhang, J. Phys. Chem. C, 2014, 118, 4043-4049.

11. Y. Zhang, J. Qian, W. Xu, S.M. Russell, X. Chen, E. Nasybulin, P. Bhattacharya, M.H. Engelhard, D. Mei, R. Cao, F. Ding, A.V. Cresce, K. Xu, J.G. Zhang, Nano Lett., 2014, 14, 6889-6896.

12. F. Ding, W. Xu, G.L. Graff, J. Zhang, M.L. Sushko, X. Chen, Y. Shao, M.H. Engelhard, Z. Nie, J. Xiao, X. Liu, P.V. Sushko, J. Liu, J.G. Zhang, J. Am. Chem. Soc., 2013, 135, 44504456.

13. Y. Liu, D. Lin, P.Y. Yuen, K. Liu, J. Xie, R.H. Dauskardt, Y. Cui, Adv Mater., 2017, 1605531.

14. A. Kato, A. Hayashi, M. Tatsumisago, J. Power Sources, 2016, 309, 27-32.

15. J. Qian, W.A. Henderson, W. Xu, P. Bhattacharya, M. Engelhard, O. Borodin, J.G. Zhang, Nat. Commun., 2015, 6, 6362.

16. H. Sano, H. Sakaebe, H. Matsumoto, J. Electrochem. Soc., 2011, 158, A316-A321.

17. R. Mogi, M. Inaba, S.-K. Jeong, Y. Iriyama, T. Abe, Z. Ogumi, Journal of The Electrochemical Society, 2002, 149, A1578-A1583.

18. H. Kim, J. Choi, H.-J. Sohn, T. Kang, J. Electrochem. Soc., 1999, 146, 4401-4405.

19. H. Kim, B. Park, H.-J. Sohn, T. Kang, J. Power Sources, 2000, 90, 59-63.

20. M. Jagannathan, K. S. Ravi Chandran, J. Electrochem. Soc., 2013, 160, A1922-A1926.

21. J. K. S. Goodman, P. A. Kohl, J. Electrochem. Soc., 2014, 161, D418-D424.

22. T. Fukutsuka, K. Asaka, A. Inoo, R. Yasui, K. Miyazaki, T. Abe, K. Nishio, Y. Uchimoto, Chem. Lett., 2014, 43, 1788-1790. 
23. A. Kitada, Y. Kang, K. Matsumoto, K. Fukami, R. Hagiwara, K. Murase, J. Electrochem. Soc., 2015, 162, D389-D396.

24. I. Shterenberg, M. Salama, H.D. Yoo, Y. Gofer, J.-B. Park, Y.-K. Sun, D. Aurbach, J. Electrochem. Soc., 2015, 162, A7118-A7128.

25. N. Sa, B. Pan, A. Saha-Shah, A.A. Hubaud, J.T. Vaughey, L.A. Baker, C. Liao, A.K. Burrell, ACS Appl. Mater. Interfaces, 2016, 8, 16002-16008.

26. T. Kimura, K. Fujii, Y. Sato, M. Morita, N. Yoshimoto, J. Phys. Chem. C, 2015, 119, 1891118917.

27. K. Ueno, R. Tatara, S. Tsuzuki, S. Saito, H. Doi, K. Yoshida, T. Mandai, M. Matsugami, Y. Umebayashi, K. Dokko, M. Watanabe, Phys. Chem. Chem. Phys., 2015, 17, 8248-8257.

28. G. Vanhoutte, N.R. Brooks, S. Schaltin, B. Opperdoes, L. Van Meervelt, J.-P. Locquet, P.M. Vereecken, J. Fransaer, K. Binnemans, J. Phys. Chem. C, 2014, 118, 20152-20162.

29. K. Yoshida, M. Nakamura, Y. Kazue, N. Tachikawa, S. Tsuzuki, S. Seki, K. Dokko, M. Watanabe, J. Am. Chem. Soc., 2011, 133, 13121-13129.

30. H. Moon, R. Tatara, T. Mandai, K. Ueno, K. Yoshida, N. Tachikawa, T. Yasuda, K. Dokko and M. Watanabe, J. Phys. Chem. C, 2014, 118, 20246-20256. 


\section{Figure captions}

Figure 1. Chemical structures of Mg-, Li-salts and triglyme (G3) solvent used in this study. Raman spectra of pure G3 solvent and electrolyte solutions of $x$ M Mg(TFSA $)_{2}+(1-x)$ M LiTFSA/G3 $(x$ $=0,0.1,0.5)$ in the frequency range of 780 to $900 \mathrm{~cm}^{-1}$.

Figure 2. Cyclic voltammograms of $\mathrm{Cu} / \mathrm{Li}$ cells with a Li reference electrode, corresponding to $\mathrm{Li}$ deposition/dissolution behavior on/from a Cu substrate in electrolytes of $x \mathrm{M} \mathrm{Mg}(\mathrm{TFSA})_{2}+(1-x)$ M LiTFSA/G3 ( $x=0,0.1,0.5)$. Inset: Enlarged view of the anodic profile in the range from -0.2 to $0.6 \mathrm{~V}$.

Figure 3. FE-SEM images of deposits obtained from $x$ M Mg(TFSA) $2+(1-x)$ M LiTFSA/G3: (a) $x=0$, (b) $x=0.1$, (c) $x=0.5$.

Figure 4. XRD patterns of deposits electrochemically grown on a Cu substrate in electrolytes of $0.5 \mathrm{M} \mathrm{Mg}(\mathrm{TFSA})_{2}+0.5 \mathrm{M}$ LiTFSA/G3 at each time under various constant potential.

Figure 5. (a) Photographs of deposits on Cu-foil substrate obtained from an electrolyte solution of $0.5 \mathrm{M} \mathrm{Mg}(\mathrm{TFSA})_{2}+0.5 \mathrm{M} \mathrm{LiTFSA} / \mathrm{G} 3$ under applied potential of $-0.8 \mathrm{~V}$ vs. $\mathrm{Li} / \mathrm{Li}^{+}$. (b) Time dependence of current density for the electrodeposition in $x$ M Mg(TFSA) $2+(1-x)$ M LiTFSA/G3. Inset: Enlarged view of the profile in the initial 1 hour.

Figure 6. Schematic illustration of proposed suppressing effect of Li dendritic growth by addition of Mg-salt. (a) In a commercially available electrolyte, Li deposition occurs inhomogeneously. By repeated deposition-dissolution cycling, the deposition morphology results in dendrite that causes a rapid capacity fading and thermal runway of batteries. (b) In an electrolyte containing Mg-salt, Mg-ion preferentially undergoes reduction to form metallic Mg on a substrate due to its higher standard electrode potential. Subsequently, Li deposition proceeds on the Mg and reacts with that to electrochemically form a binary Li-Mg alloy. 
Figure 7. (a) Charge-discharge curves obtained from various electrolytes at constant current condition ( $\left.0.1 \mathrm{~mA} \mathrm{~cm}^{-2}\right)$. Inset: Variation of Coulombic efficiency. (b) FE-SEM images of deposits obtained after the first charge state. 


\section{Graphical and textual abstract for the contents pages}

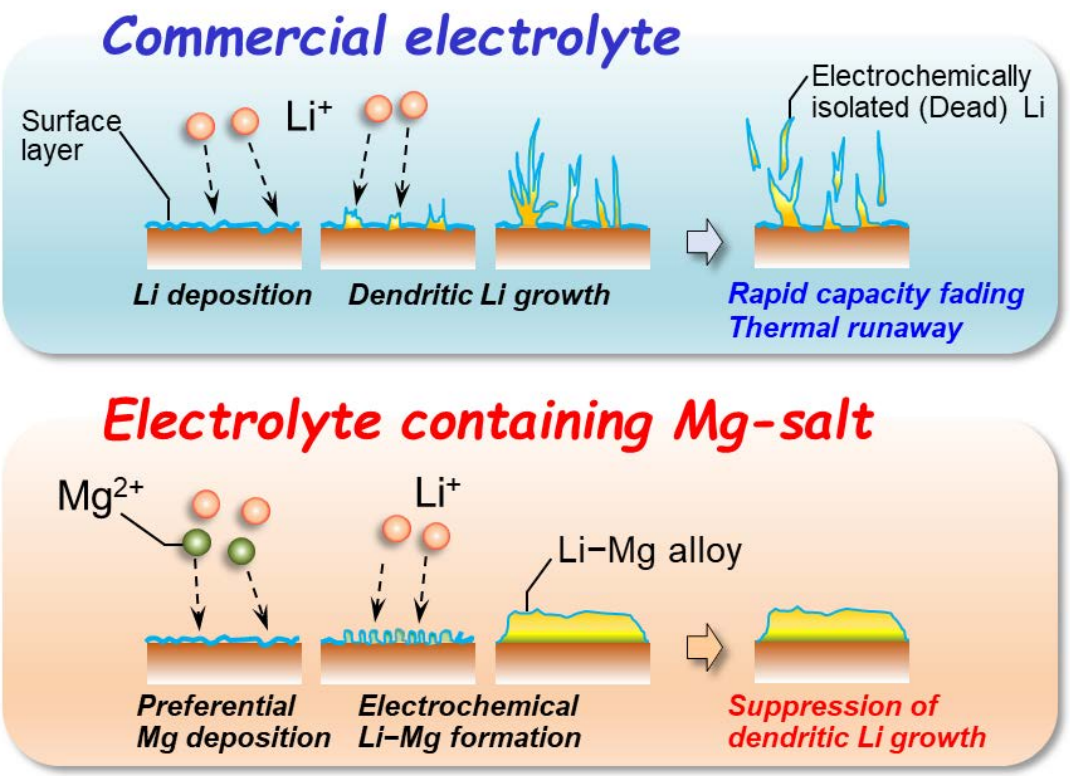




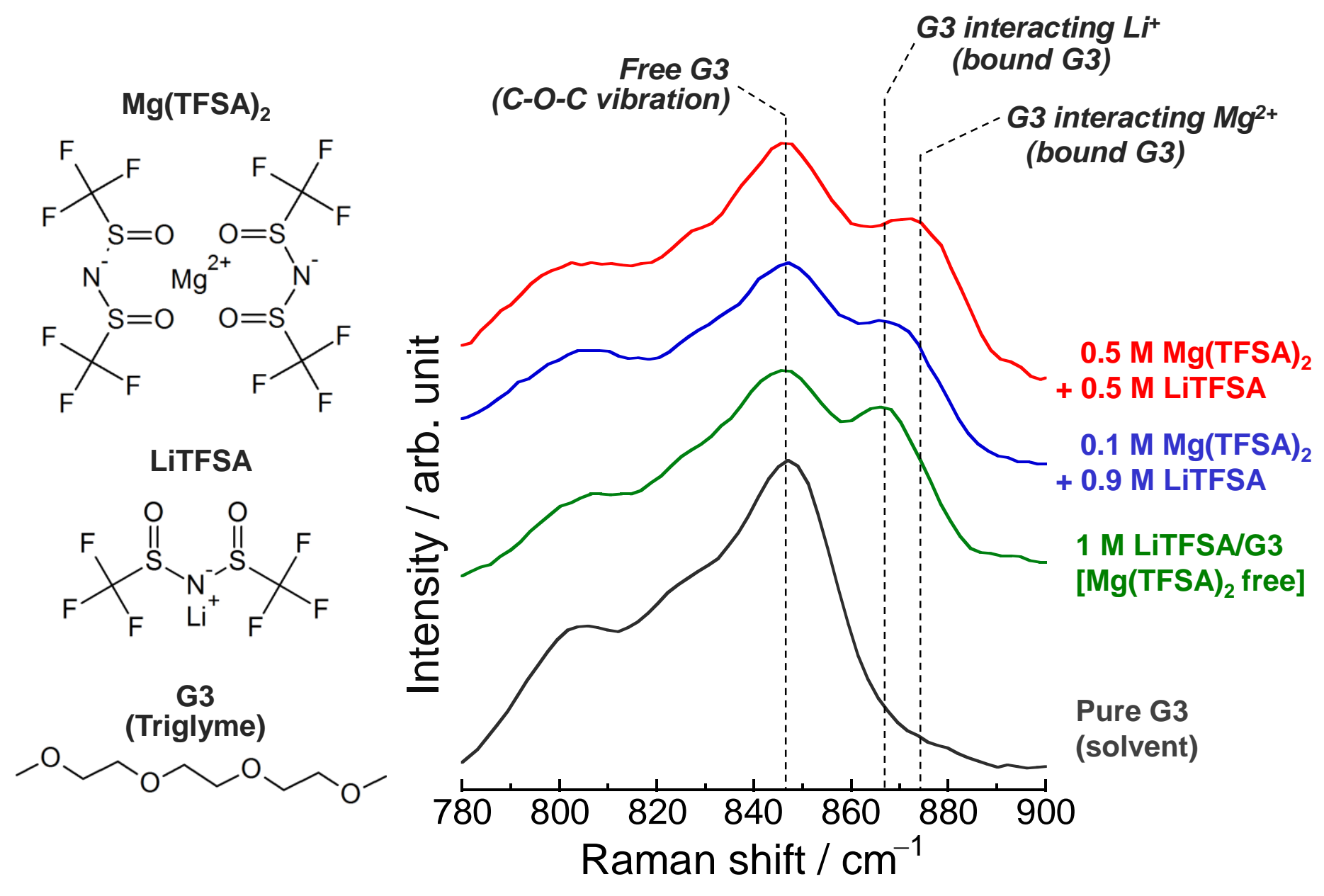

Figure 1. Chemical structures of Mg-, Li-salts and triglyme (G3) solvent used in this study. Raman spectra of pure G3 solvent and electrolyte solutions of $x$ $\mathrm{M} \mathrm{Mg}(\mathrm{TFSA})_{2}+(1-x) \mathrm{M} \mathrm{LiTFSA} / \mathrm{G} 3(x=0,0.1,0.5)$ in the frequency range of 780 to $900 \mathrm{~cm}^{-1}$. 


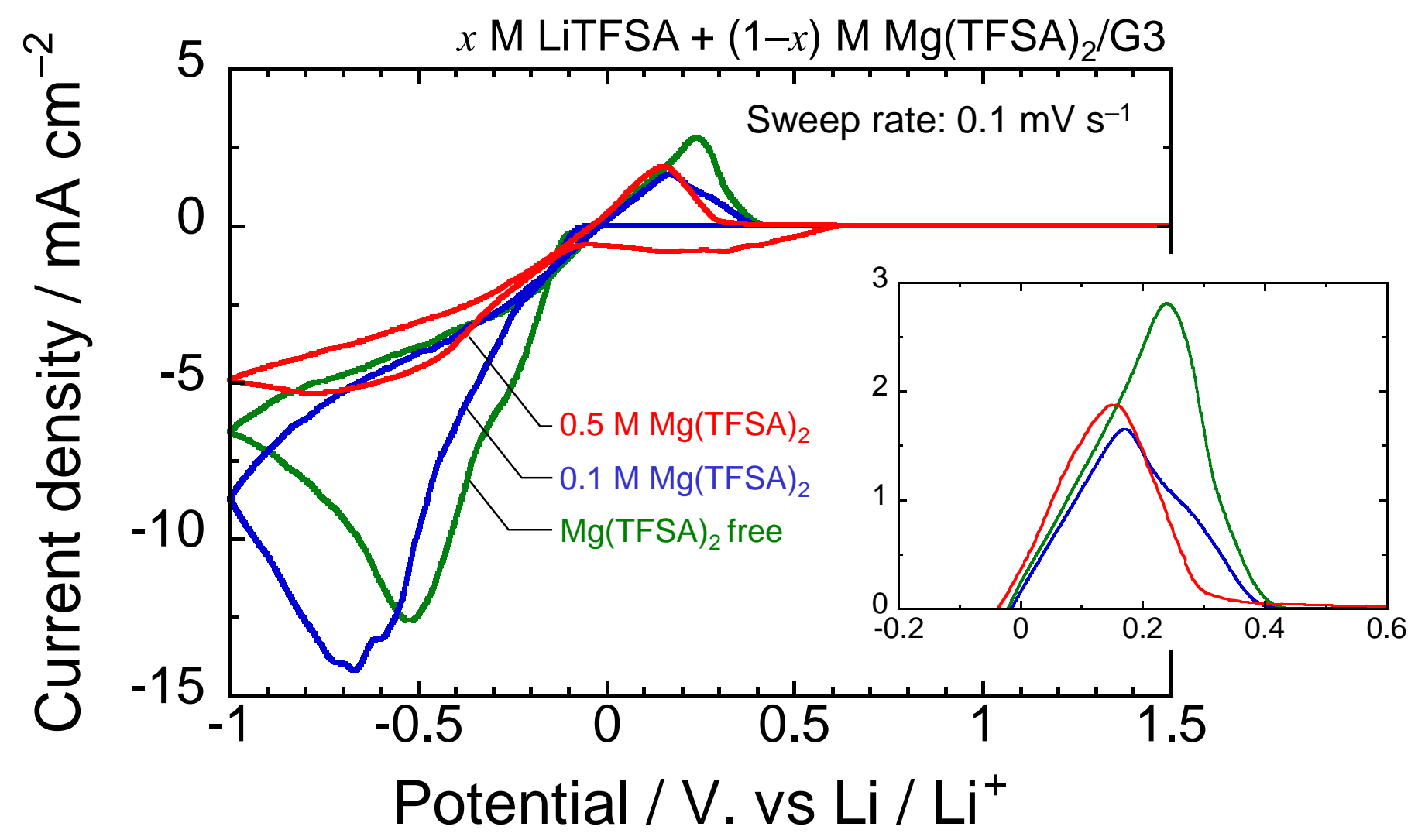

Figure 2. Cyclic voltammograms of $\mathrm{Cu} / \mathrm{Li}$ cells with a $\mathrm{Li}$ reference electrode, corresponding to $\mathrm{Li}$-deposition/dissolution behavior on/from a $\mathrm{Cu}$ substrate in electrolytes of $x \mathrm{M} \mathrm{Mg}(\mathrm{TFSA})_{2}+(1-x) \mathrm{M} \mathrm{LiTFSA} / \mathrm{G} 3(x=0,0.1,0.5)$. Inset: Enlarged view of the anodic profile in the range from -0.2 to $0.6 \mathrm{~V}$. 
(a) $1.0 \mathrm{MLJTFSA/G3} \mathrm{(Mg-salt} \mathrm{free)}$

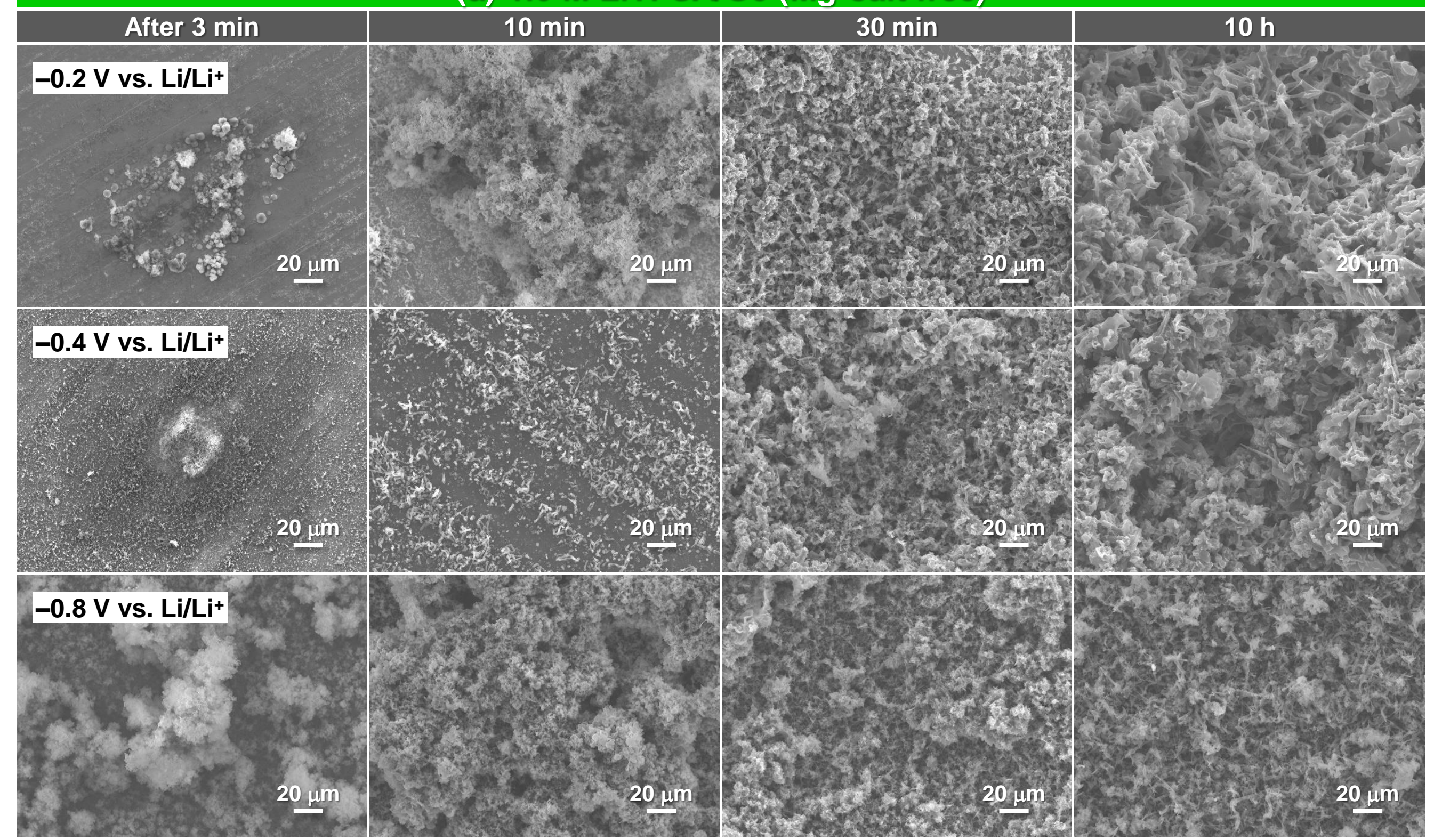

Figure 3. FE-SEM images of deposits obtained from $x \operatorname{M~} \operatorname{Mg}(\operatorname{TFSA})_{2}+(1-x)$

M LiTFSA/G3: (a) $x=0$, (b) $x=0.1$, (c) $x=0.5$. 




Figure 3. FE-SEM images of deposits obtained from $x \mathrm{M} \mathrm{Mg(TFSA})_{2}+(1-x)$ M LiTFSA/G3: (a) $x=0$, (b) $x=0.1$, (c) $x=0.5$. 

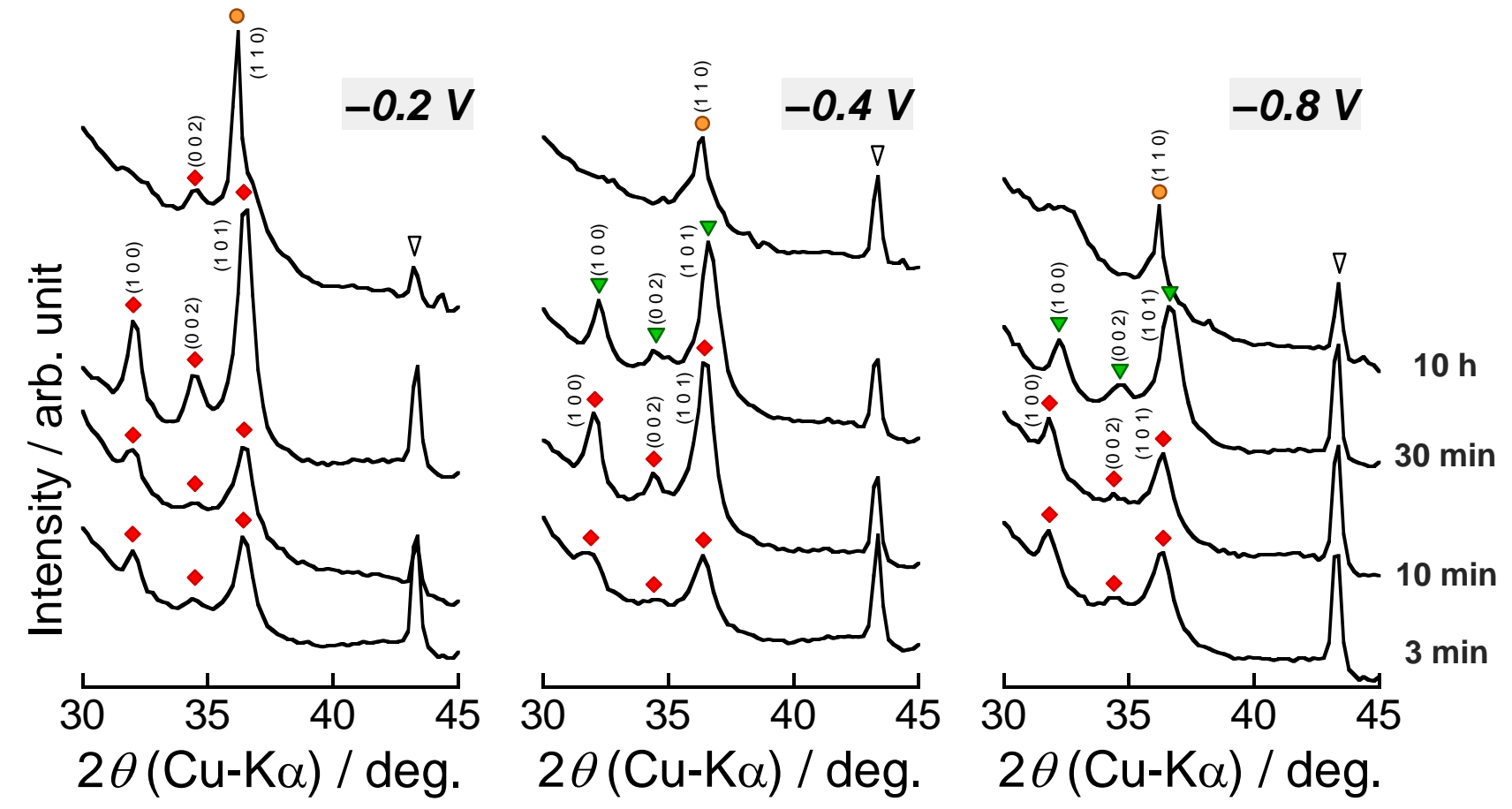

$\square \mathrm{Li}$

(ISCD:00-001-1131)

$\nabla \mathrm{Li}_{0.14} \mathrm{Mg}_{0.86}$ (ISCD:01-071-9478)

$\bigcirc \mathrm{Li}_{0.9} \mathrm{Mg}_{0.1}$ (ISCD:01-071-9480)

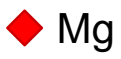

(ISCD: 01-071-4618)

$\nabla$ Cu substrate

$2 \theta(\mathrm{Cu}-\mathrm{K} \alpha) / \mathrm{deg}$.

Figure 4. XRD patterns of deposits electrochemically grown on a $\mathrm{Cu}$ substrate in electrolytes of $0.5 \mathrm{M} \mathrm{Mg}(\mathrm{TFSA})_{2}+0.5 \mathrm{M} \mathrm{LiTFSA} / \mathrm{G} 3$ at each time under various constant potential. 
Current density / $\mathrm{mA} \mathrm{cm} \mathrm{cm}^{-2}$

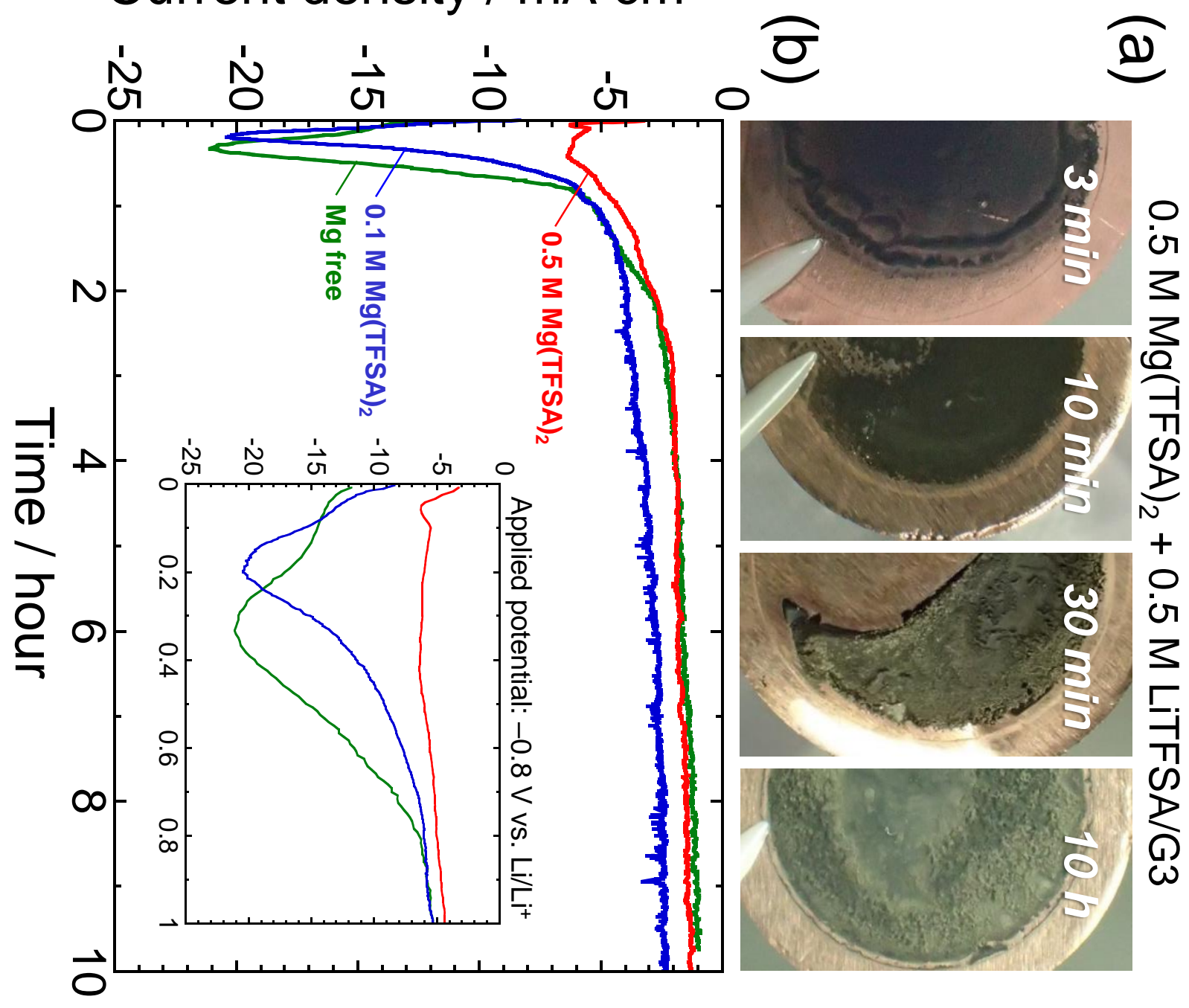

Figure 5. (a) Photographs of deposits on $\mathrm{Cu}$-foil substrate obtained from an electrolyte solution of 0.5 $\mathrm{M} \mathrm{Mg(TFSA})_{2}+0.5 \mathrm{M} \mathrm{LiTFSA} / \mathrm{G} 3$ under applied potential of $-0.8 \mathrm{~V}$ vs. $\mathrm{Li} / \mathrm{Li}^{+}$. (b) Time dependence of current density for the electrodeposition in $x \mathrm{M}$ $\mathrm{Mg}(\mathrm{TFSA})_{2}+(1-x) \mathrm{M}$ LiTFSA/G3. Inset: Enlarged view of the profile in the initial 1 hour. 


\section{(a) Commercial electrolyte}

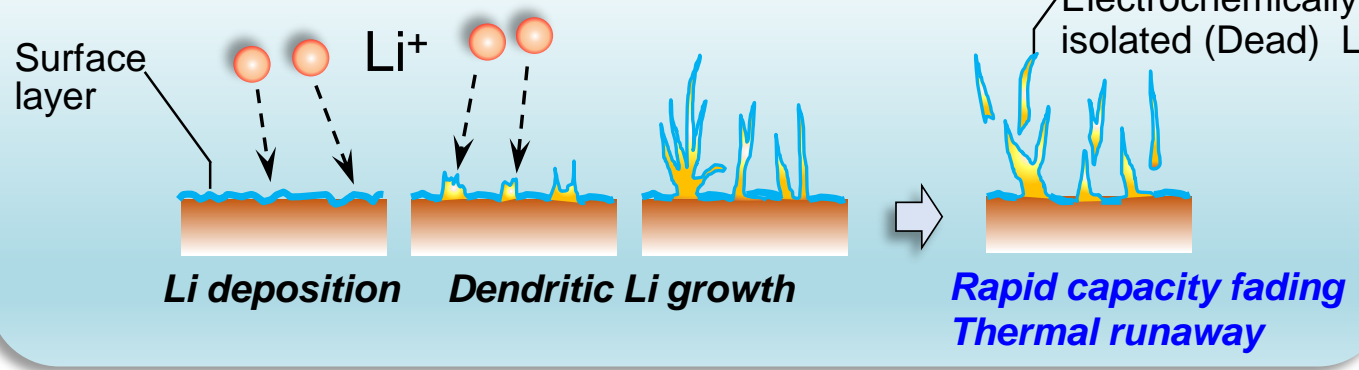

(b) Electrolyte containing Mg-salt

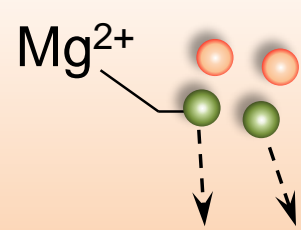

Preferential Mg deposition

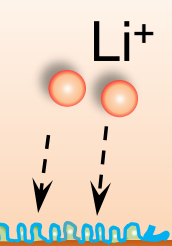

Electrochemical Li-Mg formation

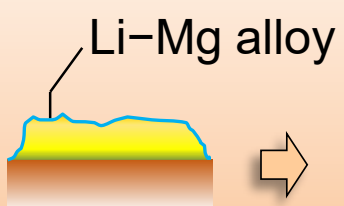

Suppression of dendritic Li growth

Figure 6. Schematic illustration of proposed suppressing effect of Li dendritic growth by addition of Mg-salt. (a) In a commercially available electrolyte, Li deposition occurs inhomogeneously. By repeated depositiondissolution cycling, the deposition morphology results in dendrite that causes a rapid capacity fading and thermal runway of batteries. (b) In an electrolyte containing $\mathrm{Mg}$ salt, Mg-ion preferentially undergoes reduction to form metallic $\mathrm{Mg}$ on a substrate due to its higher standard electrode potential. Subsequently, Li deposition proceeds on the $\mathrm{Mg}$ and reacts with that to electrochemically form a binary $\mathrm{Li}-\mathrm{Mg}$ alloy. 